\title{
Networking and Transportation Planning for Regional
}

\section{Synergism*}

\author{
Raúl O. Dichiara, Blanca I. Niel, Agustín Claverie \\ Universidad Nacional del Sur, Bahía Blanca, Argentina
}

\begin{abstract}
The development of entities involves until to achieve the final results passing through the stages of association, organization, communication and fluxes of data. The vis-a-vis congruencies from the networking field context give birth to the ensuing sequence of the previous chained concepts. Herein, we highlight the networking role specifically by the equivalence between association with networking; organization with network's architecture; communication with linkages and fluxes of data with dynamics. In addition, from any external constructive appraisal it is desirable to give synergism to the previous sequence in order to get not only a result but an efficient result. Then, we set forth three case studies in order to analyze the contribution of networking in planning to improve regional synergism. The first case is the design of a binary associative network with SMEs respondents over firm attribute dichotomies which render the archetype pattern in the surveyed assembly. The second one deals with a horizontal network architecture, of $n$ local SMEs which perform similar economic activity, in which different linkage strategies impose success or defeat to specific ensemble's aim. The third case concerns with the localization of soybean and/or wheat storing and processing plants in a heuristic interface in order to envisage real and objective planning decisions from an external appraisal in the regional logistic.
\end{abstract}

Keywords: networks, network architecture, transportation strategies

\section{Introduction}

The vis-a-vis congruencies from the networking field context give birth to the ensuing sequence of group forming, organization, communication and fluxes of data chained concepts. Herein, we highlight the networking role specifically by the equivalence between association with networking; organization with network's architecture; communication with linkages and fluxes of data with dynamics (Watts, 1999). In addition, from any external constructive appraisal it is desirable to give synergism to the previous sequence in order to get not only a

\footnotetext{
${ }^{*}$ Research project "Networks and logistic Systems Development in Freight as component of the systemic Competitiveness of the agribusiness and specific industries in Argentina” (2008-2010) led by Prof. R. O. Dichiara. Science and Technology Secretary and Economics Department. Universidad Nacional del Sur (UNS). The original version of this paper was presented at EMNet-2009 Congress, Cracovia Business School, Sarajevo.

Raúl O. Dichiara, Ph.D. in Economics, Economics Department, Universidad Nacional del Sur.

Blanca I. Niel, Chemical Engineer, Mathematics Department, Universidad Nacional del Sur. Agustín Claverie, Technician, Mathematics Laboratory, Universidad Nacional del Sur.

Correspondence concerning this article should be addressed to Raúl O. Dichiara, 12 de Octubre 1198. $7^{\circ}$ Floor, B8000CTX, Bahía Blanca, Argentina. E-mail: dichiara@criba.edu.ar.
} 
result but an efficient result. Then, we set three case studies in order to analyze the contribution of networking in planning to improve regional synergism and the more important conclusions.

\section{Methodology}

The first case is the design of a binary associative network (architecture) with SMEs respondents (entities) over firm dichotomous attributes which render the archetype pattern (result) in the respondent assembly. The network is built from the $n$ deterministic answers of $m$ respondent firms; this networking scheme of $n$ deterministic nodes associated with each firm's answer and its $n(n-1)$ array of interconnections assembles the enterprises by a non-linear updating function of each binary node of information. Particularly, its netting process handles $m \times n(n-1)$ interconnections of the storage data of these $m$ surveyed firms (datum organization). These networking structures show the existence of the virtual and/or complementary firms in the analyzed attributes among the respondent firms. Moreover, it exhibits the existence of a real or virtual anti-prototype in those characteristics. Hence, the associative technique detects intrinsic differentiated or eventually liar datum firms in the formed group.

The second network deals with a horizontal network architecture (organization) of $n$ local SMEs (entities) which perform similar economic activity (Erbe, 2008). The linkages of this equalitarian network are of $n(n-1)$ order of magnitude since each pair of enterprises has feasible communication (connectivity). If each pair of firms is linked at least once during the whole data cyclic of information flux, then there are $(n-1)$ ! options to sift out with least time and/or least cost or generally optimum weighted tour. This huge scale of alternative requires to approximate the solution by different dynamics of the data fluxes, i.e., planning decision strategies (results).

The third analysis concerns a case study related to the localization of soybean processing plants and/or wheat mills (entities with given localization) in a screen dump of a heuristic interface (Himanen, Nijkamp, \& Reggiani, 1998). Let $p$ and $q$ be, respectively, the mentioned localizations which now play the role of entities. We struggle with the $2^{p}-p-1$ and $2^{q}-q-1$ subnetting sets in separate bunch. We struggle for comparative least cost transportation studies after the integration of river and seaports; railroad and freeway facilities at regional level (result) using the versatility of adding and removing nodes of heuristic interface (Saltzer, Reed, \& Clark, 1984). In addition, we gather both comminuting grain processes in the $2^{p+q}-(p+q)-1$ subnetting instances in order to promote the misusage logistic facilities as well as to point out the need of a hub for the synergy of the regional transportation systems.

\section{The Binary Associative Network}

We implement a synchronous parallel artificial network associating a two-state unit to each deterministic answer of SMEs about dichotomous attributes related with social, cultural and economical aspects of the polled enterprises. Accordingly, all significant responsive enterprise patterns are associated to metastable or stable binary memories. In this instance we introduce constructively a dual memory network which stores step by step each quasi-stable pattern of the respondent firm in the studied dichotomy. The connectivity matrix $W$, $W=\left(w_{i j}\right)$ an $n_{\text {even }} \times n_{\text {even }}$ dimensional array is constructed taking into account the cooperative principles that 
reduces $W$ to the projection form. Hence, each quasi-stable pattern is projected into the subspace spanned by the stable patterns. Finally, a synergistic rule, defined by a non-linear updating function of each binary node of information, recovers the network dynamics onto the original binary space of the datum exploration. Given any dichotomous respondent sequence of $n_{\text {even }}$ whole length, the responsive pattern associated to this structure $\vec{\xi}=\left(\xi_{i}\right)$ is an $n_{\text {even }}$ - dimensional string of "True" and "False" about selected enterprises attributes. Herein $i$ in $1 \leq i \leq n_{\text {even }}$ are the integer values of the position variable giving along the respondent sequence $\vec{\xi}$ of $n_{\text {even }}$ overall length.

Therein, $\xi_{i}=1$ if the firm in the $i$ th analyzed feature engages in an affirmative (or true) answer. On the contrary, $\xi_{i}=-1$. The synergism of the network is compelled by the definition of connectivity element $w_{i j}$ as well as the rule of ignition of the nodes. Herein, $w_{i j}$ represents the feasibility of activating the unit $(i)$ given that the unit $(j)$ has been activated (or inactivated) and traces the influence of an existing unit $(j)$ on the putative unit $(i)$ for every quasi-stable or stable pattern. Moreover, the activation of each $i-$ unit as: $\xi_{i}=1$ (active) at time $t+1$ if at time $t, \sum_{j=1} w_{i j} \xi_{j}>0, \xi_{i}=-1$ (inactive) at time $t+1$ if at time $t, \sum_{j=1} w_{i j} \xi_{j}<0$, otherwise $\xi_{i}$ at time $t+1$ coincides with $\xi_{i}$ at time $t$. The collective behaviour of these non-linear networks exhibits associative properties because their stable states act as attractors. This networking process embodies an associative memory since if the network is settled in a state which is different from all stable states it will evolve until to reach one of them (Haykin, 2000).

We analyze 20 binary enterprise's features over 124 firms of the 150 polled SMEs ${ }^{1}$, i.e., the networking scheme of $n=20$ deterministic nodes associated with each firm's answer, amongst $m=124$, handles $m \times n(n-1)$ interconnections of the storage data of these surveyed firms (Dichiara, Claverie, \& Niel, 2006). The network technique combined with the level of congruence inside of the net's basins allows us to identify the candidates to be the archetype, the most associative pattern of the sample and the anti-archetype. The networks process sifts out congruent, virtual and indifferent firms in the analyzed attributes among the respondent firms. Hence, the associative procedure detects intrinsic differentiated or eventually liar datum firms in the formed group and facilitates the location of virtual or real hub firm in the spectra of considered deterministic attributes.

Each firm attribute profile is promoted as to be the most associative pattern of the studied sample attributes. In this condition, the evolution of the designed network from one to one of the sample patterns is backed up. Then the reordering of the considered firms is done taking into account the number of firm captured inside each firm sample attractor's basin. Hence, the archetype and the disassociative pattern in the sample of SMEs must be screen off from head and tail cuts of the processed data rendered by the implemented network. Finally, comparative studies of the distributions of the trapped firms in each level of accordance in the attractor's basin will crown the most associative profile. An analogous treatment of the reversed datum cut will prompt the less associative pattern in the studied dichotomous attributes of the polled SMEs (see Table 1).

\footnotetext{
1 The information was taken from the database of the research project "Estudio de impacto económico. Empresas de la Cámara de Concesionarios y Permisionarios del Puerto de Bahía Blanca”. Dichiara et al., Economics Department, UNS, August 2002.
} 
Table 1

Dichotomic Attributes of Enterprises

\begin{tabular}{|c|c|c|c|}
\hline & Attributes & $C$ & $-C$ \\
\hline 1 & Year of enterprise foundation & Before or in 1970 & After 1970 \\
\hline 2 & $\begin{array}{l}\text { Is the foundation of the enterprise related to the } \\
\text { growth of big enterprises? }\end{array}$ & Yes & No \\
\hline 3 & The enterprise is property of? & Unique owner & One society \\
\hline 4 & Education of the society members & University degree & Less than university degree \\
\hline 5 & The enterprise markets & Goods & Services \\
\hline 6 & $\begin{array}{l}\text { The enterprise has shut down recently the } \\
\text { production of some goods or services }\end{array}$ & Yes & No \\
\hline 7 & $\begin{array}{l}\text { The enterprise has recently added some new good } \\
\text { or service }\end{array}$ & Yes & No \\
\hline 8 & $\begin{array}{l}\text { Which were in } 2001 \text { the turnover (with VTA) of the } \\
\text { enterprise? }\end{array}$ & Less or equal to $\$ 1$ millón & Bigger than \$1millón \\
\hline 9 & $\begin{array}{l}\text { The trend of turnover are as follows: "growing } \\
\text { from } 1997 \text { to } 1999 \text { and decreasing between } 2000 \\
\text { and } 2001 \text { " }\end{array}$ & Yes & No \\
\hline 10 & $\begin{array}{l}\text { Do the SME have ties with more than two big } \\
\text { enterprises? }\end{array}$ & Yes & No \\
\hline 11 & $\begin{array}{l}\text { Does the relation come with the big enterprise from } \\
\text { one public option? }\end{array}$ & Yes & No \\
\hline 12 & The normal period of the contract is: & Less or equal to one year & Other \\
\hline 13 & Are the contracts renewed? & Yes & No \\
\hline 14 & $\begin{array}{l}\text { Does the interrelation with the big enterprise } \\
\text { include "Improvement of Quality and technical } \\
\text { level"? }\end{array}$ & Yes & No \\
\hline 15 & $\begin{array}{l}\text { Has the enterprise made investments in the period } \\
1997-2001 \text { ? }\end{array}$ & Yes & No \\
\hline 16 & $\begin{array}{l}\text { Has the enterprise incorporated new technology } \\
\text { and improvements? }\end{array}$ & Yes & No \\
\hline 17 & $\begin{array}{l}\text { Does the enterprise organize training courses for } \\
\text { the employees? }\end{array}$ & Yes & No \\
\hline 18 & $\begin{array}{l}\text { Has the enterprise participated with other big } \\
\text { enterprises in teaching training courses for the } \\
\text { employees? }\end{array}$ & Yes & No \\
\hline 19 & $\begin{array}{l}\text { Has the enterprises strategic alliances with other } \\
\text { SMEs in the last years in order to satisfy demands } \\
\text { of big customers? }\end{array}$ & Yes & No \\
\hline 20 & $\begin{array}{l}\text { Was that association promoted for some of those } \\
\text { big enterprises? }\end{array}$ & Yes & No \\
\hline
\end{tabular}

Note. Source: Own elaboration.

We shortlist the first six top ranked firms as potential candidates for the associative archetype of the SME sample. For brevity's sake, both candidates that were neck and neck in the race to be the recipient as the associative archetype in the group were ordinal location firms at $51 \mathrm{st}$ and $52 \mathrm{nd}$, with binary attributes $140780^{2}$ and $134652(\equiv-1,-1,1,-1,-1,-1,-1,-1,1,1,-1,1,1,1,1,1,1,1,-1,-1)$. Firm 51 st in the sample trapped 123 firms and left only one firm pattern at indifferent position. Meanwhile, firm 52nd in the sample trapped 120

\footnotetext{
2 The decimal number representation of each boolean vector in a backward process, e.g.,-1, 1, 1, 1, -1, -1, 1, -1, -1, 1, -1, $-1,1,-1$, $-1,1,-1,1,1,1,1,-1,-1 \equiv 0,1,1,1,0,0,1,0,0,1,0,0,1,0,0,1,0,1,1,1,1,0,0 \equiv 0 \times 2^{0}+0 \times 2^{1}+1 \times 2^{2}+1 \times 2^{3}+1 \times$ $2^{4}+1 \times 2^{5}+0 \times 2^{6}+1 \times 2^{7}+0 \times 2^{8}+0 \times 2^{9}+1 \times 2^{10}+0 \times 2^{11}+0 \times 2^{12}+1 \times 2^{13}+0 \times 2^{14}+0 \times 2^{15}+1 \times 2^{16}+12^{17}+1 \times 2^{18}+0$ $\times 2^{19} \equiv 468156$.
} 
firms and left three firm patterns at indifferent position. However, since 40 over 77 of the service firms trapped inside of 52nd's basin have level of affinity superior to 0.85 , under the same circumstances, firm 51 st caught only 19 firms and the remainder lies down in the 51st's basin with level of affinity inferior or equal to 0.8 . Both SME's basins gross up similarly the inferior levels of affinity with 43 manufacturing firms (Dichiara et al., 2006). The 51 st company engages with "maintenance of asphalt" and "cleaning up with water at high pressure" Meanwhile, the 52nd firm's activities are: "scaffolding assembly", "transportation of waste materials" and "cleaning up with water at high pressure". The differential aspects between them are rooted in the facts that the binary pattern of the firm 52nd translates the economical difficulties of the period. From the negative response to: Did the firm "recently" incorporate any new product or offer any new service? and the confirmation of following the scheme of "increasing from 1997 to 1999 and afterwards decreasing" in the tendency of the firm's turnover. However, the firm has done improvements or incorporated technology during the period 1997-2001. On the other way round, we look for the less associative pattern in the sample amongst the bottom ranked firms.

The less integrated candidates are the companies with 1st and 31st ordinal positions and with boolean features rebuilt from 966655 and 860468 decimal numerical representations. A vis-a-vis comparison of the number of firm attributes capture at any upper level of affinity inside the basins crowns firm 1st as the disassociative sample archetype. Firm 1st activities are: "Marketing of rare, industrial and medicinal gases, transportation of these gases, assembly of installations". As an ancillary comment, but by no mean trivial for the economical aspects, 1st firm's doings are differentiated because no one else in the group is engaged in this kind of activities. The mainstream in the whole deterministic sample is trapped by the string of attributes of the firm 52nd, i.e., $-1,-1,1,-1,-1,-1,-1,-1,1,1,-1,1,1,1,1,1,1,1,-1,-1$. On the contrary, the spray sheep of the considered sample, firm 1st, has the following 20 boolean answers $1,1,1,-1,1,-1,1,1,1,1,1,1,1,1,1,1,1,1$, 1, 1. In addition, the technique exhibits the virtual character of every anti-SME's basin.

\section{A Horizontal Network Architecture of $\boldsymbol{n}$ Local SMEs}

In today's marketplace it is imperative to promote co-operation among the small enterprises. Subnetting between one another small firms which perform similar economic activity made easy to improve the capability of each enterprise's member for survival (Lind, 2003). Since co-operation is equivalent to facilitate connections, we propose subnet's architectures that envisage member firms in undistinguishable node locations, i.e., each enterprise has equal hierarchy and is complete connected. Although every pair link is weighted taking into account the slightest and strongest differences of social, economical and cultural attributes that have been analyzed from the data. Therefore, the proposed methodology allows us to enhance individual firm connectivity inside its own subnet by driving distinct strategies to overcome forthcoming challenges. Our proposal in order to promote cooperation in the SME's sector involved in similar economic activity is sustainable underneath of the egalitarian principle that "every firm in its specific subnet has the equal availability of been connected to any of the other enterprise subnetted member". From the networking terminology this egalitarian principle means complete connectivity.

Therefore, the subnet architecture weighted the slight, mild and strong differences between the members of each economic activity when they are located in the vertices of a regular $n-$ gon. Moreover, there are natural associated integers to the pair of edges between nodes which make easiest to handle different linkage strategies. 
Moreover, the employed methodology allows us to determine the existence of any feasible strategy of connection in the subnet under the requirement that every subnetted enterprise has been linked once only over a single cyclic linkage. In other words, each of the subnetted firm has a unique opportunity to take part in the cycle of the decision. In addition, if it is given the situation in which certain bonds had formed between pairs of subnetting firms, the technique confirms the viability or unfeasibility of constructing cyclic connections with that predetermined links.

The linkages of this equalitarian network structure are of $n(n-1)$ order of magnitude since whichever pair of enterprises has feasible communication. The constraint that each pair of subnetted firms is linked at least once during the whole data cyclic of information flux imposes $(n-1)$ ! feasible cycles to explore in order to sift out those engaged in least time and/or least cost, etc.. This huge scale of alternative requires of the approximation techniques, e.g., greedy, anti-greedy, nearest neighbour, farthest neighbour, heuristic algorithm, to reach the optimum (quasi-optimum) solutions of a specific aim. After the firms' aggregation, the methodology renders the existence or absence of full connectivity and all feasible connections since from the beginning of the disclosure we merge the words "connectivity" and "cooperation" as synonyms in any net, sub-net or hub sub-net architecture (see Table 2).

Table 2

Selected Binary Attributes of Enterprises

\begin{tabular}{|c|c|c|c|}
\hline & Attributes & $C$ & $-C$ \\
\hline 1 & Year of enterprise foundation & Before or in $1970=1$ & After $1970=-1$ \\
\hline 2 & $\begin{array}{l}\text { Is the foundation of the enterprise related to the } \\
\text { growth of big enterprises? }\end{array}$ & Yes $=1$ & No $=-1$ \\
\hline 3 & The enterprise is property of? & Unique owner $=1$ & One society $=-1$ \\
\hline 4 & $\begin{array}{l}\text { Which were in } 2001 \text { the turnover (with VTA) of } \\
\text { the enterprise? }\end{array}$ & $\begin{array}{l}\text { i) }(\$ 0 \text { a } \$ 50,000] \\
\text { ii) }(\$ 50,000 \text { a } \$ 100,000] \\
\text { iii) }(\$ 100,000 \text { a } \$ 160,000] \\
\text { iv) }(\$ 160,000 \text { a } \$ 300,000] \\
\text { v) }(\$ 300,000 \text { a } \$ 1,000,000] \\
\text { vi) }(\$ 1,000,000 \text { a } \$ 1,500,000] \\
\text { vii) }(\$ 1,500,000 \text { a } \$ 3,000,000] \\
\text { viii) }(\$ 3,000,000, \ldots]\end{array}$ & \\
\hline 5 & $\begin{array}{l}\text { Does the SME market with the big enterprises of } \\
\text { the petrochemical complex? }\end{array}$ & Yes $=1$ & No $=-1$ \\
\hline 6 & $\begin{array}{l}\text { Number of employees of the enterprise from } 0 \\
\text { until } 40 \text { with threshold of } 5\end{array}$ & & \\
\hline 7 & $\begin{array}{l}\text { Has the enterprise participated with other big } \\
\text { enterprises in teaching training courses for the } \\
\text { employees? }\end{array}$ & Yes $=1$ & $\mathrm{No}=-1$ \\
\hline 8 & $\begin{array}{l}\text { Does the enterprise come in contact with } \\
\text { universities, institutes and training centers? }\end{array}$ & Yes $=1$ & No $=-1$ \\
\hline
\end{tabular}

Note. Source: Own elaboration.

For example, $\mathrm{N}_{6}^{E}$ 's subnet is built with suppliers related to the "road construction machinery" needs in the economic region. These firms supply soil compaction equipment and in general machineries like padfoot, smooth drum, crane, excavator, crawler, caterpillar, dozer, forkleft, truck, scraper, loader, trailer, etc.. Moreover, the enterprises provide maintenances and services for the machinery, however they do not have the machineries for sale. 


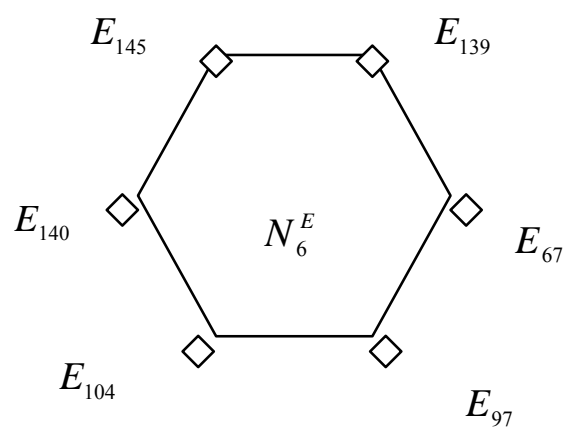

Figure 1. Nearest neighbour strategy in $\mathrm{N}_{6}^{E}$ 's subnet.

Each $\mathrm{N}_{6}^{E}$ 's enterprise member specific location abides with the rule of clockwise decreasing of the average turnover as well as of the amount of steady employees, from the starter node, that is to say from the best positioned firm, herein, the enterprise $E_{140}$. Hence, the strategy of connecting step by step between less differentiated firms is $E_{140} \rightarrow E_{145} \rightarrow E_{139} \rightarrow E_{67} \rightarrow E_{97} \rightarrow E_{104} \rightarrow E_{140}$ (see Figure 1). On the contrary, the strategy of connecting step by step between quasi-opposite or opposite firms is $E_{140} \rightarrow E_{139} \rightarrow E_{97} \rightarrow E_{145} \rightarrow$ $E_{104} \rightarrow E_{67} \rightarrow E_{140}$ (see Figure 2).

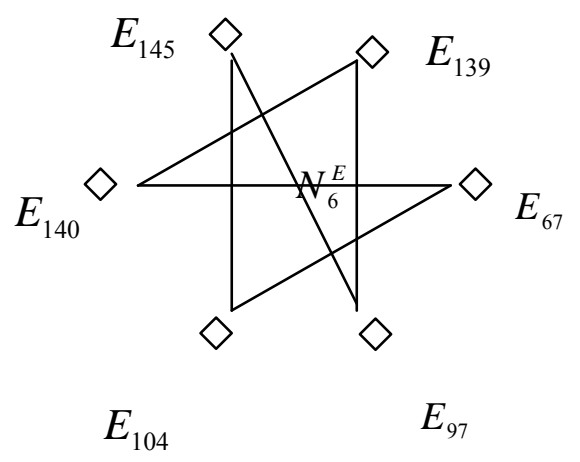

Figure 2. Antithetic to greedy strategy in $\mathrm{N}_{6}^{E}$ 's subnet.

The application of this methodology releases the existence of at least one cyclic connectivity ( $E_{140} \rightarrow E_{139}$ $\rightarrow E_{97} \rightarrow E_{104} \rightarrow E_{145} \rightarrow E_{67} \rightarrow E_{140}$ ) given a supposed strategy composed by four links between quasi-opposite firms and a unique bond between nearest feature firms and one connection between opposite ranked firms. On the other hand, if the constraints were two links of each one of the available weighted connections, the method renders the absence of any cyclic strategy of linkage for the six firms integrated in $\mathrm{N}_{6}^{E}$ 's subnet. The linkage $E_{140} \rightarrow E_{139} \rightarrow E_{67} \rightarrow E_{140} \rightarrow E_{139} \rightarrow E_{67} \rightarrow E_{140}$ foresees the redundancy of the case (Niel, 2007).

The ensuing paragraph deploys a hub subnet scheme built by a horizontal peripheral architecture of SME's and a hub firm that eventually has whichever size and is engaged in another economic activity. The hub enterprise starts and ends up the cyclic information flux. Let $\mathrm{N}_{H 7}^{E}$ be the hub subnet of "providers of electrical, electronic and/or computerized system service" constructed with the small firms $\left\{E_{8}, E_{45}, E_{71}, E_{73}, E_{89}, E_{128}, E_{135}\right\}$ and the role of the concentrator played by $H_{7}^{E}$. The paradigm of farthest neighbour renders the longest connectivity, i.e., $H_{7}^{E} \rightarrow E_{135} \rightarrow E_{89} \rightarrow E_{71} \rightarrow E_{73} \rightarrow E_{45} \rightarrow E_{8} \rightarrow E_{128} \rightarrow H_{7}^{E}$ (see Figure 3). 


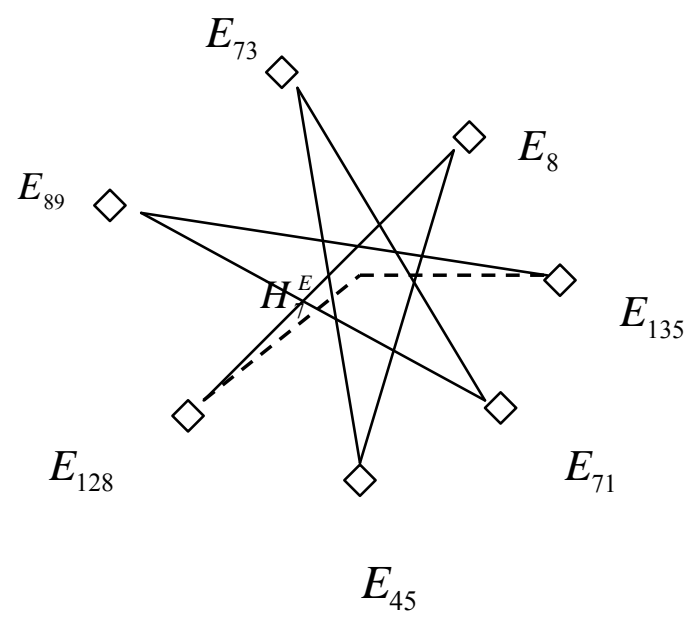

Figure 3. Farther neighbour paradigm in $\mathrm{N}_{H 7}^{E}$ hub subnet.

The nearest neighbor step by step linkage renders the shortest feasible connectivity, i.e., $H_{7}^{E} \rightarrow E_{135} \rightarrow E_{8}$ $\rightarrow E_{73} \rightarrow E_{89} \rightarrow E_{128} \rightarrow E_{45} \rightarrow E_{71} \rightarrow H_{7}^{E}$ (see Figure 4).



Figure 4. Nearest neighbour paradigm in $\mathrm{N}_{H 7}^{E}$ hub subset.

\section{Case Study: Soybean and Wheat Regional Transportation Facilities}

Argentina's primary export range is the lower Paraná River ports, within $270 \mathrm{~km}$ of Argentina's most intensive grain producing region and about $200 \mathrm{~km}$ from the centre of that country's primary soybean producing region. Rosario's area of influence is prime in economic agriculture concerns, a real logistics and export corridor, however Bahía Blanca's region has many challenges to overcome (Fuller, Yu, Fellin, Lalor, \& Krajewski, 2001).

Furthermore, Bahía Blanca and Quequén are two deep sea Argentina's ports and principal export locations for wheat within $250 \mathrm{~km}$ of Argentina's southern wheat production region. The geographic scope of these both ports goes beyond and reaches the soybean production area due to its increasing international demand and its non-transgenic quality (Third World Network Biosafety Information Service, 2004) (see Table 3). 
Table 3

Argentine Grain Production (2000-2010)

\begin{tabular}{lllllll}
\hline Year & Soybean (\%) & Corn (\%) & Wheat (\%) & Sunflower (\%) & Sorghum (\%) & $\begin{array}{l}\text { Total } \\
\text { (thousands Ton.) }\end{array}$ \\
\hline $2000 / 2001$ & 42 & 25 & 24 & 5 & 4 & 64.213 \\
$2001 / 2002$ & 45 & 23 & 22 & 6 & 4 & 66.355 \\
$2002 / 2003$ & 51 & 22 & 18 & 5 & 4 & 68.563 \\
$2003 / 2004$ & 48 & 23 & 22 & 5 & 3 & 66.336 \\
$2004 / 2005$ & 47 & 25 & 20 & 5 & 4 & 79.587 \\
$2005 / 2006$ & 55 & 20 & 17 & 5 & 3 & 73.596 \\
$2006 / 2007$ & 52 & 24 & 16 & 4 & 3 & 90.184 \\
$2007 / 2008$ & 50 & 24 & 18 & 5 & 3 & 92.190 \\
$2008 / 2009$ & 55 & 23 & 15 & 4 & 3 & 56.442 \\
$2009 / 2010$ & 59 & 26 & 8 & 3 & 4 & 88.698 \\
\hline
\end{tabular}

Note. Source: Own elaboration on data from www.agrositio.com and MAGPA.

Bahía Blanca's harbour is located southwest Buenos Aires province, $670 \mathrm{~km}$ from Buenos Aires city, Argentina's District Capital (see Figure 5). Given $p$ communities in the region of Bahía Blanca's harbour engaged in agriculture economy related to cropping, storage and processing grains (specifically wheat, sunflower, sorghum and soybean) and $q$ locations with analogous role in the area of Quequén sea port, we analyze the logistic facilities of each region as two economic basins and then as one unified development area.

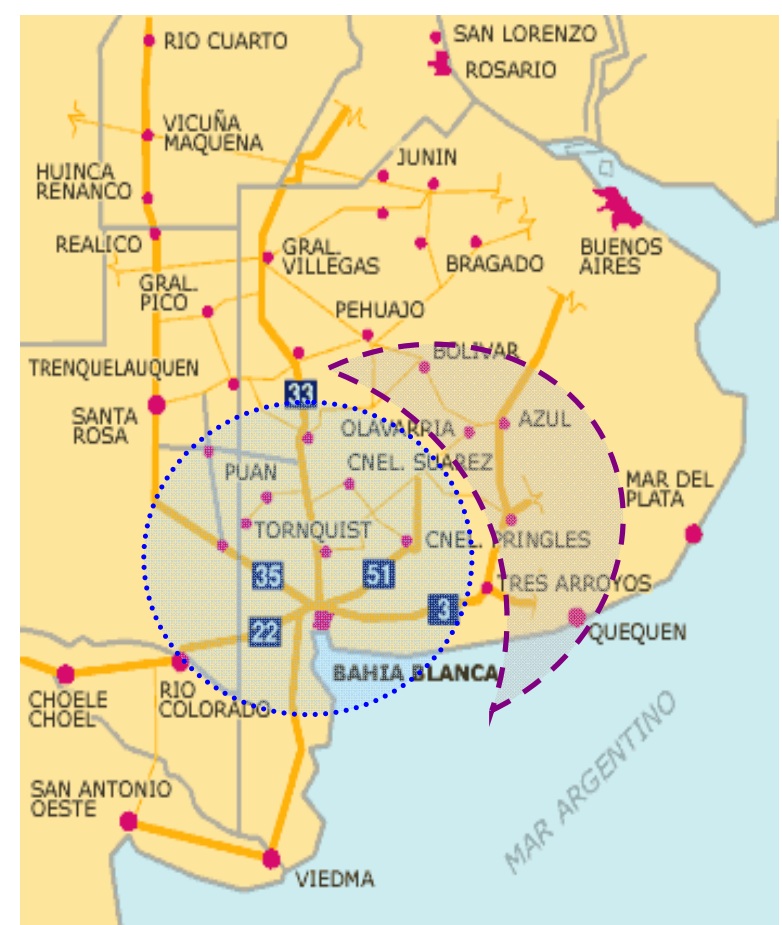

Figure 5. Coarsely representations of Bahía Blanca and Quequén ports linkages. Retrived from http://www.puertobahiablanca.com.

The first spatial ring associated to each harbours is respectively the surroundings of the hills named "Sierra de La Ventana" and "Sierra de Tandil". First shortest tour surroundings Sierra de la Ventana is: Bahía Blanca $\rightarrow 33$ natl. $r d: \rightarrow$ Tornquist $\rightarrow$ Pigué $\rightarrow$ Guaminí $\rightarrow 85$ prov. $r d: \rightarrow \rightarrow$ Coronel Suarez $\rightarrow$ Coronel Pringles $\rightarrow$ 
Tres Arroyos $\rightarrow 3$ natl. $r d . \rightarrow$ Coronel Dorrego $\rightarrow$ Bahía Blanca $^{3}$. The first shortest tour surroundings Sierra de Tandil is: Necochea $\rightarrow 86$ prov. $\quad r d . \rightarrow$ Benito Juárez $\rightarrow 3$ natl. $\quad r d . \quad$ (nearby) Azul $\rightarrow 226$ natl. $r d . \rightarrow$ Tandil $\rightarrow$ Balcarce $\rightarrow 55$ prov. $r d . \rightarrow$ Necochea.

In the beginning, Bahía Blanca's harbour was linked to a widespread railroad network, which reached Buenos Aires and Paraná river ports. Besides, it extended to other provinces such as Río Negro, Neuquén, La Pampa and the south of Córdoba. That railroad network corresponds to bygone time and consequently many hamlets of the region under consideration fade or cease to exist. Bahía Blanca captures a closed zone in relation to this harbour. Herein, the wheat production travels to the sea port from one of these peripheral roads.

In whole this region, freight is moved predominantly by truck on a system of roads that vary in quality from almost-good to very poor. Trucks are the dominant mode used to move raw material from production areas to port and conversely, inputs to processors and re-export points. A rational strategic plan to develop the transportation infrastructure implies a significant cost of realizing. Although, if priorities are being set by the public administration with the private sector taking part in order to overhaul the economic regional system.

A feasible second ring for Quequén port embraces the tour: Necochea $\rightarrow 88$ prov. $r d . \rightarrow$ Mar del Plata $\rightarrow 226$ natl. $\quad r d . \rightarrow$ Balcarce $\rightarrow$ Tandil $\rightarrow$ (nearby) Azul $\rightarrow$ Olavarría $\rightarrow$ San Carlos de Bolívar $\rightarrow$ Pehuajó $\rightarrow 86$ prov. $r d . \rightarrow$ Henderson $\rightarrow$ Daireaux $\rightarrow$ General Lamadrid $\rightarrow$ Laprida $\rightarrow$ A. Gonzáles Cháves $\rightarrow$ San Cayetano $\rightarrow$ Energía $\rightarrow 228$ natl. $r d . \rightarrow$ Necochea.

Let $p$ be the set integrated by 33 communities ${ }^{4}$ in Bahía Blanca area. Meanwhile, $q$ is conformed by 20 other locations ${ }^{5}$ in Quequén port area. Then, the feasible clusters of communities for Bahía Blanca's basin is $2^{p}-p-1$, i.e., 8589934558 and for Quequén's basin $2^{q}-q-1$, i.e., 1048555. If both basins are integrated in a single economic region this association yields the ludicrous figure of $2^{p+q}-(p+q)-1$, i.e., 9007199254740938 (Reggiani \& Fabbri, 1999, Eds.). However, feasible community aggregations do not have neither maritime nor terrestrial facilities and their logistics resources are scarce. The viable clusters are far from the theoretical possibilities.

Apart from geographical hampered junctions, the real constraints are the national, provincial and county roads and the railway system. In the absence of clear division for the regional grain production basins of both consecutive Atlantic ports, the overlapping of pinpointed tours is highly probably. From historic and geographic reasons Bahía Blanca's port captures farmers' wheat and soybean productions faraway from its wharves, nor less than $350 \mathrm{~km}$. In addition, its surroundings are characterized by high quality human and technological resources, which are vital for public administration, finance, trade and industry of a widespread area as well as a very privileged location for consumption hinterland. It is worth to mention that Bahía Blanca's port facilities have wharves to handle containers, general cargo, chemical, petrochemical and oil by products from industrial plants in its surroundings (Dichiara, 2003, 2006). Besides, Quequén's port is near close to the most fertile soil for

\footnotetext{
${ }^{3}$ Acronyms for national road (natl. rd); provincial road (prov. rd) and cross roads (natl. $\times$ prov. rd)

4 Bahía Blanca, Pigué, Guaminí, Trenque Lauquen; Coronel Borrego, Tres Arroyos, Cabildo, Coronel Pringles; Cross road prov. rd. 86-prov. rd. 51; Coronel Suarez, General Lamadrid, Olavarría, Casbas, Daireaux, Guaminí, Pehuajó, Darregueira, Macachín, Catriló, Quemú Quemú, Jacinto Arauz, General Acha, Toay, General Pico, Santa Rosa, Médanos, La Adela, Mayor Buratovich, Stroeder, Pedro Luro, Río Colorado, Carmen de Patagones, Viedma\}. A clustered human settlement from hamlets to cities characterized by urban agricultural societies, engaged in grain or livestock production, chemistry and machinery.

5 Necochea, Lobería, Tres Arroyos, Tandil, Azul, Benito Juárez, Balcarce, Mar del Plata, Ayacucho, A. González Chavez, Laprida, Bolívar, Azul, Rauch, Cacharí, Tapalqué, General Alvear, San Carlos de Bolívar, Henderson\}.
} 
producing crops. Therefore, it is associated to the core of the southeast farmer crop production area.

Finally, both integrated economies have the challenges to improve roadway and railway networks as a first stage to play a role in order to improve this region faster economy development (Pearson, 2009). The concern of the public policy is not only funnelling grain from the farmers at a low retrieval incomes to the hands of foreign and domestic exporters but deploys its industrial potential by comminute and manufacturing grains nearby to both ports locations (Jyne, Ballard, \& Nijhoff, 2006).

\section{Conclusion}

The SMEs surveyed firms as well as the regional communities constituted the entities of three studied cases of networks built by cooperative principles. In detail, an associative network with SMEs, a horizontal architecture of SMEs and its hub-net variation and a full linkage structure between pair of regional communities.

Each network's dynamics renders the archetype of the surveyed SMEs; the pathways of feasible and optimum strategies and the shortest viable tours. These gathering of entities under an implemented organization and dynamics unveil knowledge about of several social, cultural, regional and economic aspects. In conclusion, if a regional hub harbour is promoted by government planning of updating the roadway and railway networks goods and services must be imported and exported properly within it. Hence, business has the advantage of a logistics and distribution solution available in the surroundings and it deters hinterland community desertions. Furthermore, cost savings and faster turn-around decrease the rate of death of SMEs and will realize regional synergism.

\section{References}

Dichiara, R. O. (2003). Relationships between small and big enterprises in suppliers networks. The case of mass production industry. Belfast, 1, 211.

Dichiara, R. O. (2006). La participación de la industria petroquímica en la operatoria del consorcio del puerto de Bahía Blanca In S. Gorenstein, \& V. Viego (Eds.), Complejos Productivos basados en recursos naturales y desarrollo territorial (pp. 193-205). Estudios de casos en Argentina. EdiUNS, Bahía Blanca.

Dichiara, R. O., Claverie, A., \& Niel, B. I. (2006). Dual memory searches for dis and associative prototypes in small and medium-sized enterprises. The 2006 Conferences Best of Bahía Blanca, Argentina.

Dichiara, R. O. (2008). University Research and Education Requirements for Small and Medium Sized Enterprises. Programme ALFA (2000-2005). ISBN 987-9871171-99-6. EdiUNS, Bahía Blanca, p. 456.

Dichiara, R. O., \& Niel, B. I. (2008). Fostering connectivity in specific subnets of small and medium-sized enterprises. AMSE MS'08, Universitat de les Illes Balears, Spain.

Erbe, H. H. (2008). Creation and management of networks of small and medium-sized enterprises (R. O. Dichiara, Ed.). op. cit.

Fuller, S., Yu, T., Fellin, L., Lalor, A., \& Krajewski, R. (2001). Effects of improving South America's transportation system on the international competitiveness in world grain markets. Texas A\&M University, Department of Agricultural Economics, TAMRCInternational Market Research Report No. IM-2-01, October 2001.

Haykin, S. (2000). Neural networks: A comprehensive foundation (2nd ed.). Prentice Hall.

Himanen, V., Nijkamp, P., \& Reggiani, A. (1998). Neural networks in transport applications. England: Ashgate Publishing Ltd..

Jyne, T. S., Ballard, Z., \& Nijhoff, J. J. (2006). Stabilizing food markets in eastern and southern Africa. Managing Food Price Risks and Instability in a Liberalizing Market Environment. Elsevier.

Lind, P. (2003). Management of change: A guide to analysing change projects. Sweden: Linköping University.

Niel, B. I. (2007). On a general method for finding the longest traveling salesman paths in specific networks. Proceedings of the XIV Congress of SIGEF. University of Craiova, Poaina Brasov, Romania. 
Pearson, M. (2009). Australia wheat exports delayed on port congestion. Ship chartering. Baltic Dry Index.

Reggiani, A., \& Fabbri, D. (1999). Network developments in economic spatial systems: New perspectives. Ashgate Publishers.

Saltzer, J. H., Reed, D. P., \& Clark, D. D. (1984). End-to-end arguments in system design. ACM Transactions on Computer Systems.

Third World Network Biosafety Information Service. (2004). Document of Third World Network Biosafety, June. Retrieved from http:// www.twnside.org.sg/title/service93.htm

Watts, D. J. (1999). Small worlds: The dynamics of networks between order and randomness. Princeton Studies in Complexity.

Windsperger, J., Cliquet, G., Hendrikse, G., \& Tuunanen, M. (2007). Economics and management of franchising networks. Heidelberg: Physica-Verlag. 